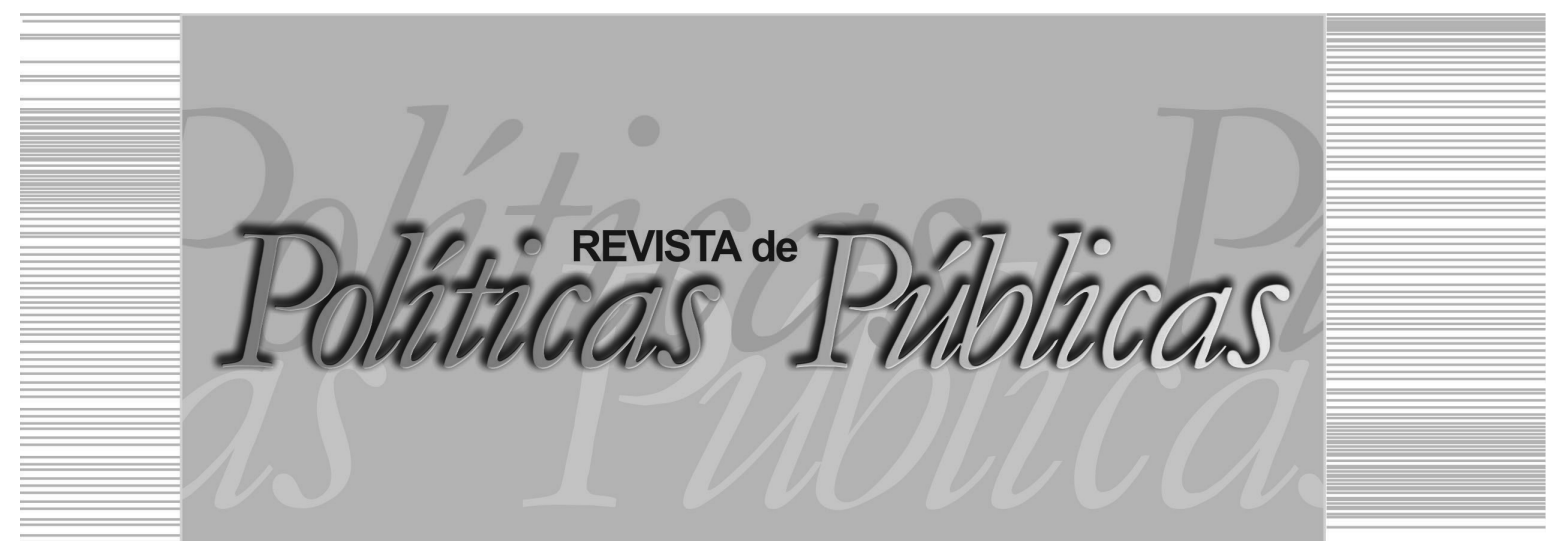

\title{
POLITICA PÚBLICA DE ASSISTÊNCIA SOCIAL E SUSTENTABILIDADE EM MUNICÍPIOS DO BAIXO AMAZONAS: a Proteção Social Básica em questão
}

\author{
Patrício Azevedo Ribeiro ${ }^{1}$ \\ Universidade Federal do Amazonas (UFAM) \\ Débora Cristina Bandeira Rodrigues ${ }^{2}$ \\ Universidade Federal do Amazonas (UFAM)
}

\section{Resumo}

Este artigo faz uma análise da política pública de Assistência Social no âmbito da operacionalização da Proteção Social Básica nos municípios de Maués e Parintins, no Baixo Amazonas, tendo como referência a abordagem conceitual de sustentabilidade social, sobretudo, quanto ao acesso, equidade na oferta dos serviços e enfrentamento da vulnerabilidade social. Apresenta uma pesquisa de natureza qualitativa realizada entre os anos de 2013 e 2014 cujos resultados apontam que em Maués e Parintins, a Assistência Social é uma política com grandes potenciais para contribuir com o cotidiano dos usuários que buscam participar dos serviços socioassistenciais. Contudo, sua operacionalização se constitui de limites e desafios em razão da precariedade nas condições físicas, materiais e humanas de funcionamento dos CRAS; das condições geográficas e territoriais que dinamizam a Amazônia; bem como do parco atendimento

Assistente Social, Mestre em Serviço Social e Sustentabilidade na Amazônia pela Universidade Federal do Amazonas (UFAM), Professor do Curso de Serviço Social da UFAM. E-mail: patricio_azevedo@yahoo.com.br

2 Assistente Social, Doutora na área de Gestão da Inovação em Biotecnologia pela UFAM, Professora do Departamento de Serviço Social e do Programa de Pós-Graduação em Serviço Social e Sustentabilidade na Amazônia (PPGSSA) da UFAM. E-mail: deb.band@ gmail.com / Universidade Federal do Amazonas - UFAM: Campus Universitário "Dorval Varela Moura"- Rua Paraíba, 2186, Palmares, Parintins - AM. CEP: 
quanto ao acesso e efetividade dos serviços socioassistenciais voltados para o enfrentamento da vulnerabilidade social dos usuários.

Palavras-chave: Assistência Social, sustentabilidade, Baixo Amazonas.

\section{PUBLIC POLICY OF SOCIAL ATTENDANCE AND SUSTAINABILITY IN MUNICIPAL DISTRICTS OF THE}

LOW AMAZON: the Basic Social Protection in subject

Abstract: This article makes an analysis of the public policy of Social Attendance in the extent of the operationalization of the Basic Social Protection in the municipal districts of Maués and Parintins, in Low Amazon, tends as reference the conceptual approach of social sustainability, above all, as for the access, justness in the offer of the services and struggle of the social vulnerability. It is a research of qualitative nature accomplished among the years from 2013 to 2014 whose results appear that in Maués and Parintins, the Social Attendance is a politics with great potentials to contribute in the daily of the users that you/they look for to participate in the social assistance services. However, his/her operationalization is constituted of limits and challenges in reason of the precariousness in the physical conditions, materials and human of operation of CRAS; of the geographical and territorial conditions that dynamize the Amazonian; as well as of the scanty service as the access and effectiveness of the social assistance services gone back to the social vulnerability struggle of the users. Keywords: Social attendance; Sustainability; Low Amazon

\section{INTRODUÇ̃̃O}

O início do século XXI marca um novo momento para a política de Assistência Social cujas mudanças assentam-se no plano teórico e operacional a partir da consolidação da Política Nacional de Assistência Social (PNAS) de 2004, do Sistema Único de Assistência Social (SUAS) de 2005, Tipificação Nacional dos Serviços Socioassistenciais de 2009, reformulação da Lei Orgânica da Assistência Social (LOAS) de 2011 e a Norma Operacional Básica (NOB/ SUAS) de 2012.

Percebe-se nessa movimentação da referida política uma preocupação em operacionalizar seus programas, projetos, benefícios e serviços socioassistenciais na perspectiva da sustentabilidade, de modo a contribuir para o enfrentamento da vulnerabilidade social que amealha grande parcela da população brasileira.

Em relação à sustentabilidade, é compreensível dizer que seu aspecto conceitual vem sendo debatido de forma ampla, por isso não se tem um entendimento unívoco, seja no âmbito acadêmico ou na 
mídia de um modo geral. Desse modo, na ótica de alguns autores (SACHS, 2002; GUIMARÃES, 2001; BELLEN, 2007) seu debate perpassa por questões ligadas às dimensões ambientais, econômicas, culturais, políticas, territoriais e sociais.

A dimensão social da sustentabilidade, foco de discussão neste trabalho, é entendida como a busca pela equidade e acesso aos direitos sociais, porquanto, qualidade de vida para toda sociedade, sobretudo aquelas situadas nos países com baixa empregabilidade, dificuldades de acesso a escola, saúde e infraestrutura básica. Esta compreensão vai ao encontro dos objetivos da Proteção Social Básica (PSB) afiançada na PNAS, que busca fortalecer as relações e vínculos sociais dos usuários como forma de enfrentamento à vulnerabilidade social.

Partindo desse pressuposto, o artigo procede a análise da política pública de Assistência Social no âmbito da operacionalização da PSB nos municípios de Maués e Parintins, no Baixo Amazonas, tendo como referência a sustentabilidade social, sobretudo, quanto ao acesso, equidade na oferta dos serviços e enfrentamento da vulnerabilidade social da população usuária.

As discussões em pauta constituem parte da pesquisa realizada entre 2013 e 2014 na área urbana dos municípios de Maués e Parintins, que subsidiou a elaboração de uma Dissertação de Mestrado apresentada ao Programa de Pós-Graduação em Serviço Social e Sustentabilidade na Amazônia (PPGSSA). Assim, o artigo ancora-se na pesquisa bibliográfica e de campo seguindo a abordagem qualitativa, cujos dados foram colhidos com os Gestores municipais da Política de Assistência Social, Coordenadores e profissionais de Centros de Referência de Assistência Social (CRAS) e Mulheres beneficiárias dos Serviços Socioassistenciais dos CRAS.

$\mathrm{O}$ artigo está sequenciado em três partes. A primeira aborda questões sobre políticas públicas e sustentabilidade nas sociedades com produção capitalista. A segunda discute o panorama da Assistência Social no contexto amazônico, momento em que traz a análise dos dados da pesquisa de campo à luz da sustentabilidade social. Por fim, a partir dos resultados da pesquisa, apresenta-se proposta de novos caminhos de concretização da política de Assistência Social numa perspectiva sustentável. 


\section{SUSTENTABILIDADE E POLÍTICAS PÚBLICAS EM PAUTA}

A discussão sobre o conceito de sustentabilidade faz parte de um debate processual no contexto da sociedade planetária que é marcada pela vigência do modo de produção capitalista. A forma como vêm se alargando as matrizes conceituais da referida expressão, algumas vezes evidenciadas no bojo de formulação e operacionalização das políticas públicas, deixam margem para compreensão de que se trata de um termo dinâmico com ganhos teóricos significativos e controversos.

De acordo com Leff (2011) a abordagem conceitual de sustentabilidade emerge no contexto do discurso da globalização econômica, particularmente, a partir da década de 1960, momento em que se presencia uma série de fóruns e eventos internacionais, tendo em vista o agravamento das problemáticas socioambientais geradas pelo uso indiscriminado dos recursos naturais pelas sociedades urbanas industriais capitalistas, ocasionando profundas mudanças na relação homem-natureza, ao mesmo tempo, impondo a necessidade de se pensar novas estratégias de desenvolvimento, tanto para os países desenvolvidos quanto para os que estão em desenvolvimento. Desse modo, postulava-se que para chegar a uma proposta de desenvolvimento sustentável seria necessário questionar as próprias bases do modo de produção predominante, sobretudo nas sociedades ocidentais.

No âmbito desse debate, Nascimento (2012) explica que a noção de sustentabilidade tem raízes fincadas em duas origens. A primeira embasada no campo das ciências biológicas. Refere-se à capacidade de recuperação e reprodução dos ecossistemas em face das agressões abusivas dos recursos naturais, tais como: desflorestamentos, terremotos, entre outros. A segunda assenta-se no debate das ciências econômicas sendo compreendida como adjetivo do desenvolvimento, em virtude do padrão de consumo crescente adotado pelas sociedades nas últimas décadas do século XX, pressupondo que tal padrão não tem possibilidade de continuar. Desta feita, tem-se a percepção da sustentabilidade em relação à finitude dos recursos naturais e sua gradativa redução, com impacto devastador sobre a vida humana, fauna e flora presentes no planeta.

Importante destacar que diversos estudos (SACHS, 1986; GUIMARÃES, 2001; NOGUEIRA; CHAVES, 2005; NASCIMEN- 
TO, 2012 entre outros) fazem referência à noção de sustentabilidade com origem na segunda linha de pensamento, apresentando maiores aprofundamentos e discussões com ideias convergentes e divergentes sobre a temática em pauta.

A crise ambiental global chama atenção para a condução do modelo de desenvolvimento adotado pelos países, a qual serve de alerta para a sociedade de um modo geral quanto à necessidade de se rever os debates e buscar alternativas para um desenvolvimento que rompa com a lógica capitalista de lucro e da riqueza material.

A década de 1970 é considerada um marco nos debates em torno da crise ambiental, isso porque, em 1972, realizou-se a Conferência Mundial sobre o Meio Ambiente Humano, em Estocolmo, momento que a questão ambiental ganhou visibilidade pública, bem como firmou as bases para a criação do Programa das Nações Unidas para o Meio Ambiente (PNUMA), órgão vinculado à Organização das Nações Unidas (ONU).

Assim, na busca por estratégias que objetivassem um desenvolvimento das sociedades de forma sustentável, ganha destaque na década de 1970 a proposta do Ecodesenvolvimento, lançada por Maurice Strong e reelaborada por Ignacy Sachs (1986). Para Sachs (1986), trata-se de um estilo de desenvolvimento adaptado, especialmente, para as áreas rurais dos países de terceiro mundo com a finalidade de luta contra a pobreza considerando as potencialidades locais, e pondo ao alcance do pequeno camponês equipamentos e técnicas apropriados de produção adaptados às suas condições econômicas e ecológicas.

A proposta do Ecodesenvolvimento emerge com fortes críticas ao modelo de desenvolvimento capitalista. Assim, encontra resistências políticas, teóricas e práticas entre os países que têm suas bases no modo de produção do capitalismo. Por conta disso, a partir da década de 1980, o supracitado termo "[...] se tornou uma palavra mal apreciada [...] e progressivamente substituída em inglês pela expressão sustainable development." (SACHS, 2009, p. 243, grifo do autor), isto é, Desenvolvimento Sustentável, o qual foi difundido no Relatório Brundtland ${ }^{1}$ apresentado em 1987 por uma comissão da ONU.

O conceito que embasa o desenvolvimento sustentável passou a ser conhecido como "[...] aquele que atende às necessidades 
do presente sem comprometer a possibilidade de as gerações futuras atenderem a suas próprias necessidades." (COMISSÃO MUNDIAL SOBRE MEIO AMBIENTE E DESENVOLVIMENTO, 1991, p. 46). Desenvolvimento este que incorpora nos seus objetivos o discurso de uma sustentabilidade na perspectiva de longo prazo, sem questionar a lógica do sistema capitalista, responsável, em grande medida, pelo acelerado processo de empobrecimento de parte da população mundial, localizados principalmente nos países considerados subdesenvolvidos e/ou em desenvolvimento.

De um modo geral, na contemporaneidade os aspectos conceituais postulados em torno da sustentabilidade não apresentam unicidade, mas princípios gerais e comuns, nas várias correntes de pensamento, que devem ser observados pelo conjunto dos governantes e sociedade em geral, a fim de garantir a permanência da vida no planeta terra. Desse modo, tal qual a realidade social, esta expressão se apresenta de maneira dinâmica e processual, necessitando ainda de muitas reflexões em torno da temática.

Guimarães (2001), Sachs (2002, 2009) e Bellen (2007) descortinam por meio de seus estudos as complexidades quanto à concretização do processo de constituição de uma sociedade sustentável, considerando a conjuntura do atual sistema de capitalismo selvagem. Por outro lado, tais autores acreditam que a afirmação de uma sustentabilidade pensada na vertente do Ecodesenvolvimento caminha na direção de alternativas para uma sociedade imbuída de conceito, onde a (re)distribuição de renda e equidade no acesso às políticas públicas são consideradas elementos fundamentais na vida dos povos.

Nessa linha de análise, Chaves (2012, grifo da autora) evidencia que do ponto de vista prático, a sustentabilidade corresponde a:

\footnotetext{
Práticas que consistem num processo de transformação no qual a exploração dos recursos, a direção dos investimentos, a orientação do desenvolvimento tecnológico e a mudança institucional se harmonizam e reforçam o potencial presente e futuro no sentido da sustentabilidade da vida humana e da construção da autonomia dos povos.
}

Sem dúvida, tal enunciado deslinda que a efetivação de uma sociedade na ótica da sustentabilidade precisa passar por transformações que caminhem para a autonomia e o protagonismo da pluralidade de povos existentes no contexto global. Nesse ínterim, 
compreende-se que falar de sustentabilidade no século XXI requer um entendimento não só ambiental ou ecológico, mais que isso; tal expressão precisa ser entendida num campo mais amplo envolvendo outras dimensões que caracterizam sua compressão, isto é, econômica, política, territorial e social (SACHS, 2002), entendendo, na ótica de Marx, que o concreto se constitui de múltiplas determinações, portanto unidade na diversidade.

Para Guimarães (2001), o conceito de sustentabilidade nos seus distintos aspectos teóricos norteia sua compreensão ampla de findar numa direção da justiça e equidade social; conservação do sistema de valores, prática e símbolos de identidade; agudiza a discussão da democracia, acesso e participação nas decisões políticas, e põe em debate a realidade plural que forma um determinado território.

Desse modo, entende-se que formular políticas públicas ou operacionalizar aquelas centradas no bem-estar da população, requer a construção de uma base teórico-conceitual ancorada na sustentabilidade entendida na perspectiva de mudança social, em vista do efetivo acesso por parte das populações às ações e serviços concretizados pelas políticas públicas. (CAVALCANTI, 2002).

Para o referido autor, "[...] o grande desafio do desenvolvimento sustentável deve ser enfrentado por políticas inteligentes [...] que possam levar a uma melhoria real das condições de vida [principalmente] das pessoas pobres [...]" (CAVALCANTE, 2002, p. 28). Nessa direção, a participação social e política se constitui requisito fundamental como ferramenta que, via de regra, contribui para o envolvimento dos setores populacionais, criando não somente expectativas consistentes, mas fomenta a responsabilidade de todos quanto às escolhas feitas na busca por soluções viáveis aos problemas estruturais presentes na sociedade.

No contexto contemporâneo, políticas inteligentes pressupõem aquelas que, no seu processo operacional, levem em consideração as particularidades regionais do Brasil, e contribuam para fortalecer e potencializar o local, numa perspectiva humana e sustentável. Para tanto, a participação das populações é questão crucial, visto que, participar social e politicamente é o melhor mecanismo de organização sociopolítica para o exercício concreto da cidadania e a busca pela garantia de direitos sociais. 
Importa esclarecer que as políticas públicas, segundo Gattai e Alves (2011), são subdivididas em: a) econômicas: incluem as políticas cambial, financeira e tributária; b) territoriais: compreendem as políticas de meio ambiente, urbanização, regionalização, plano diretor participativo e de transportes; c) sociais: se estabelecem de forma setorial como educação, saúde, habitação, assistência social, entre outras, para as quais o município tem competência comum com a União e o Estado quanto à cooperação dessas esferas de poder, transferência de recursos e cooperação técnica. Sendo todas estas relacionadas complementares entre si.

No campo das políticas públicas sociais, destaca-se neste estudo a Assistência Social configurada como política de proteção social voltada para a garantia do direito e condições dignas de vida de seus beneficiários. Porquanto, conforme a PNAS (BRASIL, 2004), é uma aliada ao desenvolvimento humano e social e não deve ser assistencialista, nem tão pouco se resume em prover necessidades ou vulnerabilidades sociais; é muito mais que isso, pois contribui para $\mathrm{o}$ acesso a bens e recursos, de modo que seus beneficiários alcancem o protagonismo e emancipação.

\section{PANORAMA DA POLÍTICA PÚBLICA DE ASSISTÊNCIA SOCIAL NA AMAZÔNIA E NO AMAZONAS}

A Assistência Social faz parte do quadro sócio-histórico de formação da Amazônia. Seguindo os ditames do cenário nacional, na realidade amazônica sua emergência histórica se dá por meio de práticas caritativas e de benemerência, passando pelo estágio de política pública e afirmando-se na atualidade como política que tem muito a contribuir para o desenvolvimento social e humano das populações.

Nesse sentido, Teixeira (2008) argumenta que para falar de Assistência Social na Amazônia pressupõe considerar o território amazônico no sentido heterogêneo. Tal heterogeneidade se expressa na exuberância e riqueza dos recursos naturais, no complexo da biodiversidade, no universo de povos e culturas, na ganância do capitalismo que destrói e avança no desmatamento do verde, na ideologia dos ditos projetos de desenvolvimento pensados na lógica da modernização conservadora, enfim, num mosaico que não permite entendê-lo de maneira homogêneo. Logo, a importância da Assistência Social neste emaranhado da formação regional. 
POLITICA PÚBLICA DE ASSISTÊNCIA SOCIAL E SUSTENTABILIDADE EM

MUNICIPIOS DO BAIXO AMAZONAS: a Proteção Social Básica em questão

Este entendimento é reafirmado por Maciel (2002, p. 134) ao registrar que

[...] a assistência social precisa considerar, em sua elaboração, os modos de articulação/regulação da vida cotidiana na heterogeneidade e complexidade da Região [Amazônica], para, em sua intervenção assistencial, fortalecer as redes mais frágeis presentes na luta pela sobrevivência diária. Este é, sem dúvida, um dos maiores desafios práticos, teóricos e políticos para a intervenção da área assistencial.

Assim, apesar da extrema importância que tem a supracitada política, o limite de concretizá-la se dá justamente pelo fato de que, desde os anos 60 até 80 do século XX, a intervenção do Estado assentou-se, sobretudo, na lógica de ocupação da riqueza material e busca pelo capital, desconsiderando o modo de viver do povo amazônico. Essa ideia aprofundou-se nos anos 90, tendo em vista as repercussões do neoliberalismo que incidiram diretamente na forma de gestar as políticas públicas no Brasil e consequentemente na região.

A esperança de renovação da Assistência Social sobreveio com a criação da Constituição Federal (CF) de 1988 e a LOAS trazendo para o debate a descentralização e oportunizando aos municípios a municipalização de suas próprias políticas. Tal fato, conforme Teixeira (2008, p. 149), rompe com a visão padronizada de uma política que, na sua essência, sempre foi pensada "[...] para uma realidade urbano-industrial sul-sudeste". Não obstante, para uma real descentralização como pede a LOAS, é preciso fiscalização contínua com capacitação dos gestores e técnicos que atuarão na operacionalização dos serviços.

Vale enfatizar que o mais grave dessa política no contexto amazônico consiste na explicação de que, há ainda muitos governantes e gestores municipais comungando com a ideia dos valores ultrapassados da ajuda, do clientelismo, da prática do primeiro-damismo, colocando a política como instrumento de poder e formação de redutos eleitorais.

Enquanto Amazônia Legal, este território abarca 09 (nove) estados, a saber: Acre, Roraima, Rondônia, Amapá, Tocantins, Pará, Amazonas, Maranhão e Mato Grosso ${ }^{2}$. Dentre estes, o Amazonas aparece como sendo o maior em extensão territorial, inclusive do Brasil, por possuir 1.559.161,682 $\mathrm{km}^{2}$. (INSTITUTO BRASILEIRO DE GEOGRAFIA E ESTATÍSTICA, 2011). Neste território, existem 62 municípios com população total de 3.483,985 habitantes, dos quais 2.755.490 vivem na área urbana e 728.495 na área rural. 
Em relação ao número populacional do Estado do Amazonas, verifica-se um percentual elevado de pessoas situadas no quadro de extrema pobreza (renda per capita abaixo de $\mathrm{R} \$ 70,00$ ), sendo a maior incidência na área rural. Segundo os dados do Instituto Brasileiro de Geografia e Estatística (IBGE, 2011), o percentual deste público equivale a $53,94 \%$, uma diferença de $7,88 \%$ em relação ao público urbano, cujo percentual equivale a $46,06 \%$.

Nesse sentido, ao tomar como base os objetivos da Assistência Social na PNAS (BRASIL, 2004), verifica-se que, ao lado de outras políticas públicas deve assegurar, para a população brasileira, e mais especificamente a amazonense, ações de intensa contribuição na medida em que sua operacionalização deve ocorrer de forma equânime, justa e acessível aos que dela necessitam. Entretanto, esta condição de política permanece enquanto desafio de efetivação frente ao cenário de ofensiva neoliberal que não exclui a região amazônica. Isto remete ao entendimento de Cavalcanti (2002) ao abordar a implementação das políticas públicas de forma sustentável, pois se a Assistência Social não se efetiva como preconizada, a mesma caminha na perspectiva da (in) sustentabilidade.

Seguindo o contexto nacional, no Amazonas a política de Assistência Social está pautada nas regulamentações do SUAS. Em se tratando da PSB com foco nos CRAS, o Relatório de Informações Sociais (2014) evidencia a existência de CRAS cofinanciados nos 62 municípios, o que significa um avanço neste item da política, contudo, é sabido das dificuldades e fragilidades no processo de efetivação dos serviços realizados nos CRAS. (COUTO et al., 2011). A tabela na sequência sistematiza a organização da Assistência Social quanto às instituições básicas.

Tabela 1 - Quantitativo básico de instituições organizacionais da política de Assistência Social - Brasil e Estado do Amazonas/ 2014-1

\begin{tabular}{c|cc|c|c|c|c|c|c}
\hline \multirow{2}{*}{ Instituições } & $\begin{array}{c}\text { Implantados } \\
\text { (ativos no } \\
\text { CADSUAS) }\end{array}$ & \multicolumn{6}{|c|}{ Cofinanciados pelo MDS } & \multicolumn{2}{|c|}{$\begin{array}{c}\text { Cofinanciados } \\
\text { em } \\
\text { implantação }\end{array}$} & $\begin{array}{c}\text { Lanchas de } \\
\text { Assistência } \\
\text { Social - } \\
\text { AM }\end{array}$ \\
\cline { 2 - 8 } & BR & AM & BR & AM & $\begin{array}{c}\text { Municípios/ } \\
\text { AM }\end{array}$ & BR & AM & \\
\hline CRAS & 7.989 & 90 & 7.497 & 92 & 62 & 141 & 4 & 42 \\
CREAS & 2.268 & 34 & 2.325 & 41 & 41 & 204 & 7 & \\
Centro POP & 151 & 1 & 304 & 2 & 2 & 157 & 1 & \\
\hline
\end{tabular}

Fonte: Sistematização do Pesquisador a partir do Relatório de Programas e Ações do Ministério do Desenvolvimento Social e Combate à Fome (MDS) - 2014/1. 
As informações esclarecem o quadro organizacional das instituições consideradas básicas da política de Assistência Social no Estado do Amazonas. É possível perceber que há diferenciais entre as instituições implantadas e ativas no Sistema de Cadastro do SUAS (CADSUAS) e aquelas cofinanciadas pelo MDS. No Amazonas existem 92 CRAS cofinanciados, porém, apenas 90 aparecem como ativos no CADSUAS. Compreende-se então, que uma ou duas gestões municipais não estão formalizando os registros no sistema.

Importa refletir quanto à operacionalização dos serviços socioassistenciais, uma vez que a criação de uma determinada instituição deve oferecer todos os recursos para a efetividade das ações: estrutura física adequada, recursos humanos qualificados, materiais e financeiros. Da mesma forma, os profissionais que se situam na ponta de execução do trabalho precisam assumir as atividades com compromisso ético-político e consolidá-las numa perspectiva humana, equânime e justa, contudo, precisam das condições adequadas para esse atendimento.

Destaca-se ainda, a partir da leitura da Tabela 1, a presença de lanchas da Assistência Social na realidade dos municípios amazonenses, perfazendo um total de 42. Tal questão assenta-se de suma importância em razão das peculiaridades que compõe o contexto regional. As áreas rurais e ribeirinhas dificilmente são alcançadas pelos projetos, programas, benefícios e demais ações da Assistência Social, requerendo assim um trabalho, ainda que parcial, dos profissionais que saem das sedes municipais e deslocam-se para as localidades distantes da área urbana a fim de proporcionar acesso aos serviços socioassistenciais, atuando, assim, na perspectiva de consolidação da cidadania em todo território nacional.

Do ponto de vista administrativo, o Estado do Amazonas divide-se em nove sub-regiões. Em se tratando da divisão por territórios, está dividido em dois grandes conjuntos: Territórios Rurais e Territórios da Cidadania. Neste último encontra-se o território do Baixo Amazonas que é constituído por sete municípios, os quais perfilam entre aqueles de pequeno porte: Urucará (17.094 hab.), São Sebastião do Uatumã (10.705 hab.), Nhamundá (18.278 hab.), Boa Vista do Ramos (14.979 hab.) e Barreirinha (27.355 hab.); Médio porte: Maués (52.236 hab.); e grande porte: Parintins (102.033 hab.).

Visando melhor compreender a dinâmica de organização e operacionalização da política de Assistência Social nesses municí- 
pios, cuja leitura faz-se com base na perspectiva da sustentabilidade social, a seguir destacam-se, entre os municípios do Baixo Amazonas, Maués e Parintins, os quais fizeram parte da pesquisa de campo com foco na PSB a partir do trabalho realizado nos CRAS, com destaque para as sedes dos municípios.

3.1 Proteção Social Básica em Maués e Parintins: uma análise sob ótica da Sustentabilidade Social

Maués localiza-se a leste do Estado do Amazonas, sendo que a cidade está distante da capital Manaus a $276 \mathrm{~km}$ em linha reta, o equivalente a 45 minutos por via aérea e $356 \mathrm{~km}$ via fluvial. Possui população de 52.236 habitantes; destes, 25.832 (49,45\%) são moradores da zona urbana e $26.044(50,55 \%)$ da zona rural. (INSTITUTO BRASILEIRO DE GEOGRAFIA E ESTATÍSTICA, 2011; BRASIL, 2010a). Já, a cidade de Parintins, está situada à margem direita do Rio Amazonas, fica distante da capital a $369 \mathrm{~km}$ em linha reta e 420 $\mathrm{km}$ via fluvial. $\mathrm{O}$ acesso a esta localidade é somente via aérea com duração de 50min, e/ou fluvial com aproximadamente $18 \mathrm{~h}$ de barco. O município abarca uma população de 102.033 habitantes; destes, $69.890(68,50 \%)$ estão situados na área urbana e $32.143(31,50 \%)$ contabilizados na zona rural. (INSTITUTO BRASILEIRO DE GEOGRAFIA E ESTATÍSTICA, 2011; BRASIL 2010b).

Os dados colhidos na pesquisa de campo desvelam que nos dois municípios a supracitada política encontra-se no nível de gestão plena. A NOB/SUAS (BRASIL, 2005), ao tratar dos níveis de gestão do SUAS, pondera que: neste nível de organização, significa dizer que o município tem a gestão total das ações de Assistência Social, sejam elas financiadas pelo Fundo Municipal de Assistência Social (FMAS) ou provenientes de isenção de tributos. Sobre essa questão, Silva, Araújo e Lima (2011, p. 69) observam que: "Trata-se, portando, de um nível de gestão que exige uma estrutura operacional mais ampla em termos de alocação de recursos financeiros, estruturação de equipamentos sociais e instâncias de gestão e controle social, bem como uma política de recursos humanos."

Acredita-se que a predominância do nível de gestão plena nos dois municípios expressa um avanço importante no âmbito de operacionalização da mencionada política, considerando as dificuldades estruturais e administrativas que permeiam os municípios brasilei- 
ros. Não obstante, tal nível exige que o gestor preencha alguns requisitos como forma de assegurar o trabalho realizado.

A NOB/SUAS (BRASIL, 2005) expõe sumariamente tais requisitos, dentre os quais, observou-se que alguns não estão sendo contemplados nos campos estudados: os CRAS funcionam em prédios alugados, com estrutura física e recursos materiais insuficientes para atender a demanda; não há mobiliário completo, de modo que os profissionais precisam fazer arranjo no cotidiano de trabalho ou, como argumentou uma entrevistada, é o básico-emergencial; com relação ao transporte para o desenvolvimento de atendimentos externos, não existe em nenhum dos dois CRAS.

Uma vez que os CRAS possuem instalações inadequadas, não há acessibilidade nos mesmos, bem como, para dar conta de certas demandas precisam fazer parcerias com outras instituições. Diversamente disso, "[...] o imóvel do CRAS, seja alugado, cedido ou público, deve assegurar acessibilidade para pessoas com deficiência e idosas. Constitui fator relevante para a escolha do imóvel a possibilidade de adaptação de forma a garantir o acesso a todos os seus usuários.” (BRASIL, 2009, p. 48).

Pensar a política pública de Assistência Social de forma sustentável começa pelo processo da gestão, do financiamento dos serviços, das instalações físicas adequadas com recursos humanos qualificados e materiais necessários para o desenvolvimento dos serviços. Nesse caso, os dados da pesquisa indicam que, Maués e Parintins, se encontram diante de limites para concretizar suas respectivas políticas de Assistência Social.

Sobre o trabalho desenvolvido pela PSB nos CRAS, foram delimitadas, neste artigo, duas questões centrais objetivando atender o debate sobre a sustentabilidade, em especial sua dimensão social. Nesse prisma, Sachs (2002) argumenta que a proposta de sustentabilidade social busca estabelecer um processo de desenvolvimento no qual haja distribuição equitativa de renda a fim de assegurar uma melhoria substancial nos direitos das massas populacionais. Isso implica na redução do abismo dos padrões de vida entre os detentores do capital e a classe trabalhadora. Nessa linha de pensamento, Sachs (2002, p. 85) pontua que: “[...] [prima pelo] alcance de um patamar razoável de homogeneidade social; distribuição de renda justa; em- 
prego pleno e/ ou autônomo com qualidade de vida decente; igualdade no acesso aos recursos e serviços sociais."

Percebe-se nas considerações do autor que a sustentabilidade social precisa, antes de tudo, da homogeneidade social e de garantia de renda entre todos os sujeitos. Ou seja, uma vida digna requer acesso a emprego assegurando a todos os direitos que lhes são peculiares e ascensão nos serviços públicos, os quais oportunizam ao cidadão participação efetiva nas políticas públicas.

Em consonância com essa compreensão, Guimarães (2001) salienta que a sustentabilidade social tem como objetivo maior a melhoria da qualidade de vida. Nesse ponto, chama atenção para os países subdesenvolvidos, onde os serviços públicos gravitam em torno de precariedade social.

Retomando o debate, a primeira questão é tocante às mulheres beneficiárias dos serviços, para as quais se questionou sobre o acesso, entendimento que tinham do CRAS e os motivos-bases para continuarem a participar das atividades. 
POLITICA PÚBLICA DE ASSISTÊNCIA SOCIAL E SUSTENTABILIDADE EM MUNICIPIOS DO BAIXO AMAZONAS: a Proteção Social Básica em questão

Quadro 1 - Entendimento sobre acesso, o que é o CRAS e motivos para permanência nas atividades

\begin{tabular}{|c|c|c|}
\hline & $\begin{array}{c}\text { Subcategorias elaboradas a } \\
\text { partir das falas }\end{array}$ & Transcrição de trechos das falas dos sujeitos da pesquisa \\
\hline \multirow{3}{*}{. } & $\begin{array}{l}\text { Acesso à informação e } \\
\text { conhecimentos diversos }\end{array}$ & $\begin{array}{l}\text { É uma coisa muito importante para nós, porque traz informações, } \\
\text { benefícios e sempre que preciso de algo elas me ajudam. Faz esse } \\
\text { trabalho com as crianças, né! As atividades de artesanatos e as } \\
\text { outras coisas. No meu entendimento é um momento de convivência, } \\
\text { tem sempre o apoio delas que trabalham lá (ENTREVISTADA 6). }\end{array}$ \\
\hline & Socialização & $\begin{array}{l}\text { O CRAS é uma coisa [...] boa, porque a gente vai pra lá e conhece } \\
\text { novas pessoas, a realidade delas, eu gostei de participar. É uma } \\
\text { casa das famílias, né! Só que assim [...] seria bom a gente montar } \\
\text { tipo um clube de mães, que a gente pudesse levar as coisas pra } \\
\text { fazer lá, daí eu acho que seria melhor [...] (ENTREVISTADA 3). }\end{array}$ \\
\hline & Cursos profissionalizantes & $\begin{array}{l}\text { Bom, depois que ela me convidou a ir pra lá, eu resolvi ir porque } \\
\text { eu estava precisando, né! Então, buscar mais conhecimentos, } \\
\text { porque lá gente tem informações sobre várias coisas, e a questão da } \\
\text { aprendizagem por meio dos cursos, como eu estava sem fazer nada, } \\
\text { resolvi ir (ENTREVISTADA 5). }\end{array}$ \\
\hline \multirow{3}{*}{ :. } & $\begin{array}{l}\text { Local de cuidado da família } \\
\text { Atendimento familiar } \\
\text { Socialização }\end{array}$ & $\begin{array}{l}0 \text { CRAS pra mim é uma residência boa, uma familia, que dão } \\
\text { atenção pra gente. Não tenho queixa não (ENTREVISTADA 5). } \\
\text { É legal, por que eu trago meus filhos pra cá. Eles estudam de manhã } \\
\text { e quando é a tarde a gente vem pra casa, pelo menos a gente não } \\
\text { fica só em casa, [...] fica aprendendo aqui (ENTREVISTADA 10). }\end{array}$ \\
\hline & Atendimento psicossocial & $\begin{array}{l}\text { [...] Vim em busca de algum atendimento que pudesse me ajudar. } \\
\text { Teve um tempo que tive problemas na família e foi preciso eu } \\
\text { procurar um psicólogo, daí eu era atendida no CRAS quando ainda } \\
\text { era lá naquele outro endereço. Seu Edi [psicólogo] era muito legal, } \\
\text { depois comecei a conversar com outra e isso me ajudou [...]. Eu } \\
\text { gosto daqui (ENTREVISTADA 1). }\end{array}$ \\
\hline & Cursos profissionalizantes & $\begin{array}{l}\text { É um lugar que dá oportunidade de aprender. Aqui a gente participa } \\
\text { de muitas coisas, as oficinas, as conversas com as colegas e isso } \\
\text { servi pra mim né! (ENTREVISTADA 1). }\end{array}$ \\
\hline
\end{tabular}

Fonte: Elaborado pelas autoras, 2013-2014.

Do conteúdo, depreende-se que a permanência das usuárias/ mulheres no CRAS está atrelada a diversos motivos. O primeiro refere-se ao acesso à informação e conhecimentos, visto que o atendimento nos CRAS deve propiciar ascensão a questões individuais ou familiares. Parafraseando Torres (2009), ao recorrer a uma determinada instituição da Assistência Social, o usuário espera que o profissional seja capaz de construir uma resposta profissional que dê conta de suas necessidades engendradas pelos processos heterogêneos do sistema capitalista. 
O segundo motivo diz respeito ao atendimento psicossocial. Sem dúvida, na PSB a equipe interdisciplinar lida diretamente com esta demanda com vistas a contribuir na resolução das problemáticas que lhes são apresentadas. Lidar com os usuários e suas demandas ligadas às expressões da questão social serve também como reconhecimento do saber-fazer na instituição.

Outro ponto assenta-se nos cursos promovidos para (re)inserção no mercado de trabalho. No conjunto dos serviços socioassistenciais existem as oficinas socioeducativas e profissionalizantes que proporcionam capacitação e momentos de aprendizagem. Na maioria das vezes estes cursos são promovidos a partir de parcerias com outras instituições, voltados para confecção de produtos diversos. Assim, as usuárias permanecem no CRAS porque veem neste uma porta de acesso ao mercado de trabalho seja ele formal ou informal.

Coerentemente com o que diz a PNAS (BRASIL, 2004) tem-se um último ponto o qual está relacionado ao atendimento familiar. Na oferta dos serviços socioassistenciais no CRAS, a atividade social com as famílias aparece como questão basilar; trata-se de um trabalho que envolve todos os entes familiares e, é em busca deste que muitos usuários procuram a intervenção dos profissionais que ali atuam.

As falas das usuárias para frequentar as atividades no CRAS visibilizam alguns dos elementos presentes no debate em torno da sustentabilidade social, sobretudo no que concerne à garantia dos direitos sociais e à consolidação da cidadania. Isto pode ser observado, através dos resultados da pesquisa, pela disponibilidade no acesso a informações e conhecimentos sobre seus direitos; atendimento psicológico promovendo bem-estar emocional, cognitivo e social às usuárias e famílias de modo geral; participação em cursos com qualificação sobre a produção de determinados produtos/materiais que gerem trabalho e renda; e, acima de tudo, ter uma relação familiar sólida, de diálogo e busca por objetivos coletivos. Desse modo, ainda que de forma parcial, é possível afirmar que o conjunto de serviços sociais disponibilizados nos CRAS estudados, tem possibilitado melhoria na qualidade de vida dos usuários, tendo em vista necessidade de ampliação dos serviços e garantia de inserção no mercado de trabalho por parte dos usuários, embora este último ainda não fosse possível identificar. 


\section{POLITICA PÚBLICA DE ASSISTÊNCIA SOCIAL E SUSTENTABILIDADE EM \\ MUNICIPIOS DO BAIXO AMAZONAS: a Proteção Social Básica em questão}

Nesta linha de análise, investigou-se sobre o alcance do trabalho realizado pela PSB para a prevenção da vulnerabilidade social e, por conseqüência, a potencialização, emancipação e protagonismo dos beneficiários atendidos no CRAS. As entrevistas expressam o resultado obtido.

Quadro 2 - Trabalho realizado pela PSB para enfrentamento da vulnerabilidade social

\begin{tabular}{|c|c|}
\hline $\begin{array}{l}\text { Identificação da } \\
\text { Referência de } \\
\text { Informação }\end{array}$ & Transcrição de trechos das falas dos sujeitos da pesquisa \\
\hline $\begin{array}{l}\text { Equipe de } \\
\text { Referência - } \\
\text { CRAS/Maués }\end{array}$ & $\begin{array}{l}\text { [...] Aqui é uma intervenção e nós não vamos dar conta total daquela } \\
\text { situação da família. Mas todas aquelas oficinas, orientações podem } \\
\text { contribuir. Algumas mulheres que participaram de nossas oficinas, } \\
\text { hoje já estão vendendo o que produziram [...]. E hoje, muitas mulheres } \\
\text { estão no "Mulheres Mil" [...] fazendo cursos [...]. E o legal é que está se } \\
\text { valorizando o local, se procura trabalhar fazendo produtos que podem } \\
\text { ser originar do guaraná (Coordenadora - CRAS/Maués). } \\
\text { [...] Então, penso que tudo que fazemos aqui no CRAS de alguma forma } \\
\text { influencia e contribui para potencializar os usuários, claro que não } 100 \% \text {, } \\
\text { até porque há as dificuldades, mas a gente procura atuar para que esse } \\
\text { usuário garanta mesmo que minimante, o protagonismo social (Técnico } \\
1 \text { - CRAS/Maués). }\end{array}$ \\
\hline $\begin{array}{c}\text { Equipe de } \\
\text { Referência - } \\
\text { CRAS/Parintins }\end{array}$ & $\begin{array}{l}\text { Eu vejo assim, que antes do CRAS os adolescentes estavam por ali, } \\
\text { sem fazer nada, na ociosidade, não tinham um acompanhamento, hoje } \\
\text { não. Hoje eles já têm todo esse atendimento aqui no CRAS. [...] Então } \\
\text { o CRAS é uma ferramenta de grande relevância. [...] O que as famílias, } \\
\text { principalmente as mulheres, aprendem nas oficinas, a ideia é que elas } \\
\text { possam pôr em prática e com isso contribuir no cotidiano deles mesmo } \\
\text { (Coordenador - CRAS/Parintins). } \\
\text { Eu penso que todas as atividades que são realizadas por meio do } \\
\text { PAIF, como as orientações, as palestras, as oficinas, contribuem para } \\
\text { potencializar os usuários, agora é claro que isso leva tempo e nossa } \\
\text { contribuição é muito pouco [...]. O que me traz todos os dias, apesar das } \\
\text { dificuldades que são muitas, [...], quando eu vejo que alguém sai daqui } \\
\text { com outro pensamento, de que eu sou capaz e daqui pra adiante eu } \\
\text { conduzo minha vida, então penso que esse é o melhor pagamento, a } \\
\text { melhor recompensa que a gente tem (Técnico } 2 \text { - CRAS/Parintins). }\end{array}$ \\
\hline $\begin{array}{l}\text { Mulheres } \\
\text { participantes da } \\
\text { Pesquisa/Maués }\end{array}$ & $\begin{array}{l}\text { Já aprendi alguma coisa, mas ainda não coloquei em prática, até porque } \\
\text { não tenho mais tanta idade assim pra fazer as coisas (ENTREVISTADA } \\
\text { 2). } \\
\text { Olha, eu já consigo fazer e vender o que aprendi por meio do CRAS, só } \\
\text { que assim, eu não tenho tantos recursos pra comprar mais materiais e } \\
\text { fazer novos produtos. Hoje eu até já participo da feira do produtor e vendo } \\
\text { meus artesanatos. Mas, depende muito do movimento, às vezes tá bom } \\
\text { outras não (ENTREVISTADA 4). }\end{array}$ \\
\hline
\end{tabular}




\begin{tabular}{|c|l|}
\hline $\begin{array}{c}\text { Mulheres } \\
\text { participantes da } \\
\text { Pesquisa/Parintins }\end{array}$ & $\begin{array}{l}\text { Pelo CRAS eu consegui me inscrever no Mulheres Mil e vou começar } \\
\text { agora em Abril (ENTREVISTADA 1). } \\
\text { Estou participando das atividades, não sei se lá na frente vai contribuir, } \\
\text { mas por enquanto não. As vezes até a gente aprende, a questão é eu ter } \\
\text { como fazer sozinha em casa, né! (ENTREVISTADA 2). }\end{array}$ \\
\hline
\end{tabular}

Fonte: Elaborado pelas autoras, 2013-2014.

Das falas em análise, um primeiro elemento que merece reflexão diz respeito à questão da vulnerabilidade social. Essa discussão é complexa, visto que não há unanimidade epistemológica nos conceitos. Assim, segundo o texto Orientações Técnicas sobre o PAIF (BRASIL, 2012, p. 13), no contexto da Assistência Social deve-se ficar claro que:

a) A vulnerabilidade não é sinônimo de pobreza [...]; b) [...] não é um estado, uma condição dada, mas uma zona instável que as famílias podem atravessar, nela recair ou nela permanecer ao longo de sua história; c) [...] é um fenômeno complexo e multifacetado [...], o que exige uma análise especializada para sua apreensão e respostas intersetoriais para seu enfrentamento; d) [...] se não compreendida e enfrentada, tende a gerar ciclos intergeracionais [...]; e) As situações de vulnerabilidade social não prevenidas ou enfrentadas tendem a tornar-se uma situação de risco.

Nessa ótica, o Quadro 2 sintetiza de que forma os serviços socioassistenciais operacionalizados no CRAS têm contribuído para o cotidiano de seus usuários, tanto na percepção daqueles que operacionalizam quanto dos que recebem estas intervenções. Se analisadas as falas dos interlocutores da pesquisa é possível notar que estas se complementam. Todos entendem que as atividades desenvolvidas contribuem para o estado social dos usuários dos serviços. Afirmam que a aplicabilidade das ações incide no processo da vulnerabilidade social e com isso há o protagonismo e emancipação social.

Por outro lado, esta contribuição ainda se dá de forma parcial, visto que alguns profissionais entendem que há fragilidades no atendimento realizado ao afirmarem que não contribui $100 \%$, principalmente pela existência de dificuldades. Isso é reafirmado nas falas das usuárias, pois, aprendem algo, obtêm os conhecimentos, mas nem sempre conseguem pôr em prática o que lhes foi ensinado ou orientado. Decerto que há vários determinantes para o desenvolvimento ou não dos serviços oferecidos. Citam-se: a questão da estrutura e infraestrutura, os recursos financeiros e materiais, as competências 
profissionais, bem como as condições econômicas por parte dos usuários. Importante frisar que as ações desenvolvidas pelos CRAS proporcionam ferramentas para ingresso no mercado de trabalho; são cursos voltados para panificação, doces, salgados, artesanatos, na linha do empreendedorismo, o que nem sempre consegue ser colocado em prática pelos participantes dos cursos.

Na visão de Acosta e Vitale (2010, p. 11), "[...] têm-se questionado se essas iniciativas são eficientes e eficazes para o fortalecimento das competências familiares, se respondem às necessidades das próprias famílias atendidas e se contribuem para o processo de inclusão e proteção social desses grupos.", uma vez que não atingem, ou não questionam a causa-raiz das problemáticas.

Este entendimento se insere na linha de pensamento apresentada por Sachs (2002) quando discute a sustentabilidade social que, no caso da Amazônia, para o referido autor, se faz necessário pensar o dimensionamento de sistemas de serviços sociais em domicílio, tendo em vista as condições específicas da região com variadas populações, indígenas, não indígenas, caboclos, ribeirinhos, seringueiros, entre outros. Neste caso, precisam ser adaptadas estratégias de intervenção, para que não fique restrito ao âmbito urbano o acesso à educação, saúde e outros serviços, considerando que estes são fundamentais para o funcionamento mais eficiente dos sistemas de produção local e para a melhoria das condições de vida.

Um segundo ponto de discussão diz respeito ao protagonismo e emancipação social. Isso é perceptível na leitura que se faz da PNAS (BRASIL, 2004), contudo, como garantir protagonismo e emancipação quando os serviços desenvolvidos junto aos usuários ainda são limitados e com poucas contribuições? Como a política de Assistência Social tem trabalhado em Maués e Parintins no âmbito destas expressões? É preciso fomentar a busca de autonomia pelas próprias capacidades dos sujeitos, de modo que estes possam caminhar sem a necessidade de benefícios sociais, ou seja, que tenham saída neles mesmos, inclusive entendendo suas responsabilidades individuais e familiares.

Pelo exposto, é relevante dizer que a análise da política de Assistência Social, tomando como diretriz a sustentabilidade social, tem grandes desafios de concretizar-se no contexto da sociedade capitalista. Pois, parte-se da compreensão de sustentabilidade social, conforme Mendes (2009), como aquela que engloba a satisfação de 
necessidades materiais e imateriais vislumbrando maior equidade na (re)distribuição da renda, o acesso aos direitos sociais da população menos favorecida, bem como a possibilidade de emprego que assegure qualidade de vida e igualdade no acesso aos recursos e serviços sociais, aspectos estes também preconizados na PNAS.

\section{CONCLUSÃO}

Considerando a dinâmica dos locais onde se desenvolveu a pesquisa, é possível afirmar que a Assistência Social coloca-se como política com grandes potenciais para contribuir no cotidiano de qualquer sujeito ou família que buscam participar dos serviços. Isso porque, seus objetivos indicam a necessidade de um trabalho protetivo e de fortalecimento dos vínculos familiares, porquanto, deve contribuir nas condições de vida dos usuários atendidos.

Contudo, é uma política permeada de limites e desafios o que a qualifica numa perspectiva de (in)sustentabilidade na intervenção que faz. Isso é perceptível se levado em consideração os resultados do estudo quanto à precariedade nas condições físicas, materiais e humanas de funcionamento dos CRAS; nas condições geográficas e territoriais que dinamizam a Amazônia; no parco atendimento quanto ao acesso e efetividade dos serviços socioassistenciais visando o enfrentamento da vulnerabilidade social dos usuários. Tal questão, se analisada sob o debate da sustentabilidade social, como bem mencionou Sachs (2002), prediz incompletudes na operacionalização dos serviços e que, portanto, precisam ser superados.

Diante, pois, dos desafios e limites encontrados no estudo, faz-se indicação de alguns pontos que devem ser considerados para a concretização de uma política de Assistência Social sustentável para Amazônia e, com isso, contribuir para o trabalho que vem sendo desenvolvido por esta política pública, tais como: a) gestão participativa na política de Assistência Social; b) elaboração de diagnóstico socioterritorial dos municípios; c) criação de CRAS seguindo as orientações do SUAS e adaptados ao contexto local; d) efetividade da NOB/RH no âmbito da PSB e, com isso, valorização dos profissionais; e) instrumental específico para monitoramento e avaliação das ações no CRAS; f) maior alcance de Formação e Capacitação para os trabalhadores do SUAS; g) concurso público visando a contração de trabalhadores efetivos; h) criação de Projetos municipais 
específicos na PSB como forma de complementar os serviços socioassistenciais tendo por base a realidade sociocultural local.

Faz-se necessário e urgente (re)pensar o que está posto na PNAS e nos demais materiais teórico-metodológicos do SUAS, a fim de construir alternativas de ações/intervenções que promovam mudanças reais nos diversos contextos da sociedade brasileira, em especial à população usuária dos serviços da Assistência Social na Amazônia. Isto requer maior compromisso do Estado e participação da sociedade civil na busca por consolidação dos direitos sociais constituídos.

\section{REFERÊNCIAS}

ACOSTA, A. R.; VITALE, M. A. F. Família: Redes, Laços e Políticas Públicas. (Org.). 5. ed. São Paulo: Cortez, 2010.

BELLEN, H. M. V. Indicadores de sustentabilidade: uma análise comparativa. Rio de Janeiro: FGV, 2007.

BRASIL. Ministério do Desenvolvimento Social e Combate à Fome. Secretaria Nacional de Assistência Social. Política Nacional de Assistência Social. Brasília, DF, 2004.

. Política Nacional de Assistência Social. Norma Operacional Básica - NOB/SUAS. Brasília, DF, 2005.

. Orientações Técnicas Sobre o PAIF: O

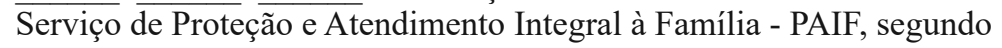
a Tipificação Nacional de Serviços Socioassistenciais. Brasília, DF, 2012. v. 1 .

Secretaria de Avaliação e Gestão da Informação. Relatório de Informações Sociais: Panorama do Município de Maués-AM segundo o IBGE - 2010. Brasília, DF, 2010a. Disponível em: $<$ http://aplicacoes.mds.gov.br/sagi/RIv3/geral/index.php?file=entra da\&relatorio $=121>$. Acesso em: 06 jun. 2013.

. Relatório de Informações Sociais: Panorama do Município de Parintins-AM segundo o IBGE-2010. Brasília, DF, 2010b. Disponível em:<http://aplicacoes.mds.gov.br/sagi/RIv3/geral/ index.php?file=entrada\&relatorio=121>. Acesso em: 06 jun. 2013.

. Sistema Único de Assistência Social. Proteção Social Básica. Orientações Técnicas: Centro de Referência de Assistência Social - CRAS. Brasília, DF, 2009. 
CAVALCANTI, C. Política de governo para o desenvolvimento sustentável: Uma introdução ao tema e a esta obra coletiva. In: (Org.). Meio ambiente, desenvolvimento sustentável e políticas públicas. 4. ed. São Paulo: Cortez. Recife, Fundação Joaquim Nabuco, 2002. p. 21-40.

CHAVES, M. do P. S. R. Serviço Social e Sustentabilidade na Amazônia: princípios da sustentabilidade. Manaus, 2012. Aula expositiva no Programa de Pós-Graduação em Serviço Social e Sustentabilidade na Amazônia.

\section{COMISSÃO MUNDIAL SOBRE MEIO AMBIENTE E}

DESENVOLVIMENTO. Relatório Nosso Futuro Comum. Tradução de Our Common Future. 2. ed. Rio de Janeiro. Fundação Getúlio Vargas, 1991.

COUTO, B. R. et al. O Sistema Único de Assistência Social no Brasil: uma realidade em Movimento. 2. ed. São Paulo: Cortez, 2011.

GATTAI, S.; ALVES, L. R. Indagar para construir políticas de gestão pública. Revista de Políticas Públicas, São Luís, v.15, n.1, p. 163-174, jan./jun. 2011.

GUIMARÃES, R. P. A ética da sustentabilidade e a formulação de políticas de desenvolvimento. In: VIANA, G.; SILVA, M.; DINIZ, N. (Orgs.). O desafio da sustentabilidade: um debate socioambiental no Brasil. São Paulo: Editora Fundação Perseu Abramo, 2001. p. 43-71.

INSTITUTO BRASILEIRO DE GEOGRAFIA E ESTATÍSTICA.

Censo Demográfico 2010. Rio de Janeiro, 2011. Disponível em: $<$ http://www.ibge.gov.br/estadosat/perfil.php?sigla $=a \mathrm{am}>$. Acesso em: 12 mar. 2013.

LEFF, E. Saber ambiental: sustentabilidade, racionalidade, complexidade, poder. Tradução de Lúcia Mathilde Endlich Orth. 8. ed. Petrópolis, RJ: Vozes, 2011.

MACIEL, C. A. B. A família na Amazônia: desafios para a Assistência Social. Revista Serviço Social e Sociedade, São Paulo, ano XXIII, n. 71, p. 122-137, set. 2002. Edição especial.

MENDES, J. M. G. Dimensões da Sustentabilidade. Revista da Faculdade Santa Cruz, Curitiba, v. 7, n. 2, p. 49-59, jul./dez., 2009.

NASCIMENTO, E. P. do. Trajetória da sustentabilidade: do ambiental ao social, do social ao econômico. Estudos Avançados, São Paulo, v. 26, n. 74, 2012. 
POLITICA PÚBLICA DE ASSISTÊNCIA SOCIAL E SUSTENTABILIDADE EM

MUNICIPIOS DO BAIXO AMAZONAS: a Proteção Social Básica em questão

NOGUEIRA, M. G.; CHAVES, M. do P. S. R. Desenvolvimento sustentável e ecodesenvolvimento: uma reflexão sobre as diferenças ideo-políticas conceituais. Somanlu: Revista de Estudos Amazônicos, Manaus, ano 5, n. 1, p. 129-143, 2005.

SACHS, I. A terceira margem: em busca do ecodesenvolvimento. Tradução de Rosa Freire d'Aguiar. São Paulo: Companhia das Letras, 2009.

Caminhos para o desenvolvimento sustentável. Organizado por Paula Yone Stroh. Rio de Janeiro: Gramond, 2002.

Ecodesenvolvimento: crescer sem destruir. São Paulo: Vértice, 1986.

SILVA, M. O. da S. e; ARAÚJO, C. C.; LIMA, V. F. S. de A.

Implantação, Implementação e condições de funcionamento do Suas nos municípios. In: COUTO, B. R. et al. (Org.). O Sistema Único de Assistência Social no Brasil: uma realidade em movimento. 2. ed. São Paulo: Cortez, 2011. p. 32-65.

TEIXEIRA, J. B. Meio Ambiente, Amazônia e Serviço Social. Revista em Pauta, Rio de Janeiro, n. 21, p. 141-152, jun. 2008. Disponível em: $<$ http://www.epublicacoes.uerj.br/index.php/revistaempauta/ article/viewFile/94/87>. Acesso em: 20 jun. 2012.

TORRES, M. M. As múltiplas dimensões presentes no exercício profissional do assistente social: intervenção e o trabalho sócio $\square$ educativo. Serviço Social em Revista, Londrina, v. 12, n.1, p. $202 \square 227$, jul./dez. 2009.

\section{NOTAS:}

1 A expressão Brundtland é referente à Gro Harlem Brundtland. Na ocasião era Ministra do Meio Ambiente da Noruega. Presidiu a Comissão Brundtland, da ONU, cujo evento voltava-se para estudos do meio ambiente.

2 A Amazônia Legal foi criada, a priori, como área de atuação da Superintendência do Plano de Valorização Econômica da Amazônia (SPVEA), cuja base está na Lei 1.806, de 06 de janeiro de 1953. Posteriormente, em 1966, criou-se a Lei 5.173 que extinguiu a SPVEA e criou a Superintendência do Desenvolvimento da Amazônia (SUDAM). Na sequência, tem-se a Lei Complementar n ${ }^{\circ}$ 31, de 11 de outubro de 1977; Medida Provisória n ${ }^{\circ} 2.146$, de 04 de maio de 2001; Lei Complementar $n^{\circ} 124$, de 03 de janeiro de 2007 que institui a SUDAM e sua área de abrangência; e a Lei 11.952, de junho de 2009, que dispõe sobre a regularização fundiária das ocupações incidentes em terras situadas em áreas da União, no âmbito da Amazônia Legal. 
